\title{
Erratum to: An Analysis of Training, Generalization, and Maintenance Effects of Primary Care Triple $P$ for Parents of Preschool-Aged Children with Disruptive Behavior
}

\author{
Cynthia L. Boyle ${ }^{1,2} \cdot$ Matthew R. Sanders ${ }^{3} \cdot$ John R. Lutzker ${ }^{4} \cdot$ Ronald J. Prinz $^{5}$ • \\ Cheri Shapiro $^{5} \cdot$ Daniel J. Whitaker ${ }^{4}$
}

Published online: 8 March 2016

(c) Springer Science+Business Media New York 2016

\section{Erratum to: Child Psychiatry Hum Dev (2015) 46:820 \\ DOI 10.1007/s10578-014-0502-2}

Conflict of interest The Triple P-Positive Parenting Program is owned by the University of Queensland (UQ). The University through its main technology transfer company UniQuest Pty Limited has licensed Triple P International Pty Ltd to disseminate the program worldwide. Royalties stemming from this dissemination activity are distributed to the Parenting and Family Support Centre, School of Psychology, UQ; Faculty of Health and Behavioural Sciences at UQ; and contributory authors. No author has any share or ownership in Triple $\mathrm{P}$ International Pty Ltd. Matthew Sanders is the founder and an author on various Triple $\mathrm{P}$ programs and a consultant to Triple $\mathrm{P}$ International. Karen Turner is an author of various Triple $\mathrm{P}$ programs. Ronald Prinz is a consultant to Triple $P$ International. Cheri Shapiro is a consultant to Triple P America.

The original version of this article unfortunately contained a mistake. The affiliations of the first author Cynthia L. Boyle were incorrect.

The correct affiliations of the author are given in this erratum.
The online version of the original article can be found under doi:10.1007/s10578-014-0502-2.

Matthew R. Sanders

matts@psy.uq.edu.au

1 Division of Violence Prevention (DVP), Prevention, Development, and Evaluation Branch (PDEB), National Center for Injury Prevention and Control (NCIPC), Centers for Disease Control and Prevention (CDC), Atlanta, GA, USA

2 University of Kansas, Lawrence, KS, USA

3 Parenting and Family Support Center, The University of Queensland, Brisbane, QLD 4072, Australia

4 Georgia State University, Atlanta, GA, USA

5 University of South Carolina, Columbia, SC, USA 